\title{
Traumatic Hemoptysis Complicating Pulmonary Amyloidosis
}

\author{
Erwan Oehler, MD ${ }^{1}$ \\ Charlotte Courtois, $M^{2}$ \\ Florent Valour, $M D^{1}$ \\ ${ }^{1}$ Department of Internal Medicine \\ ${ }^{2}$ Department of Pulmonary Medicine \\ French Polynesia Hospital Center \\ 98716 Pirae, Tahiti \\ French Polynesia
}

\section{Case Presentation}

We present a 74-year-old man admitted to hospital for a fall occurring at home. His past medical history included histologically-proven pulmonary amyloidosis followed for fifteen years (Figure 1A), without involvement of other organs.

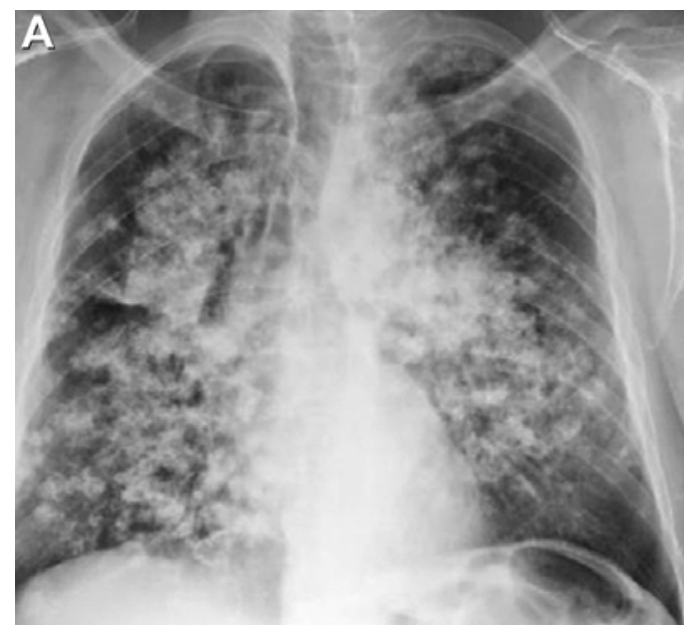

Figure 1A. Frontal chest radiography shows bilateral confluent, somewhat nodular and dense-appearing opacities with a background of faint linear and reticular opacities.

At admission, he complained of left chest pain related to a rib fracture (Figure 1B, arrow).

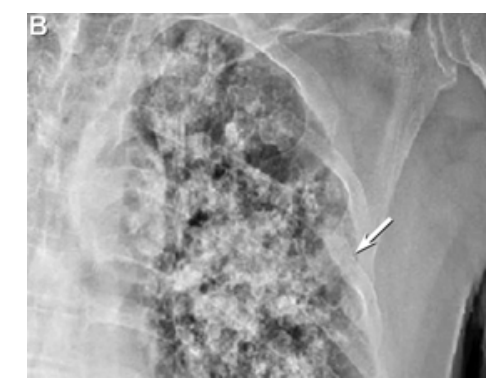

Figure 1B. Detail radiograph of the left upper thorax shows a fracture (arrow) of a posterolateral rib, superimposed on the background of dense-appearing linear and nodular parenchymal disease. 
The next day, he presented with moderate hemoptysis, prompting performance of thoracic CT (Figure 1C and D) which showed a cavity filled with material of soft tissue attenuation.

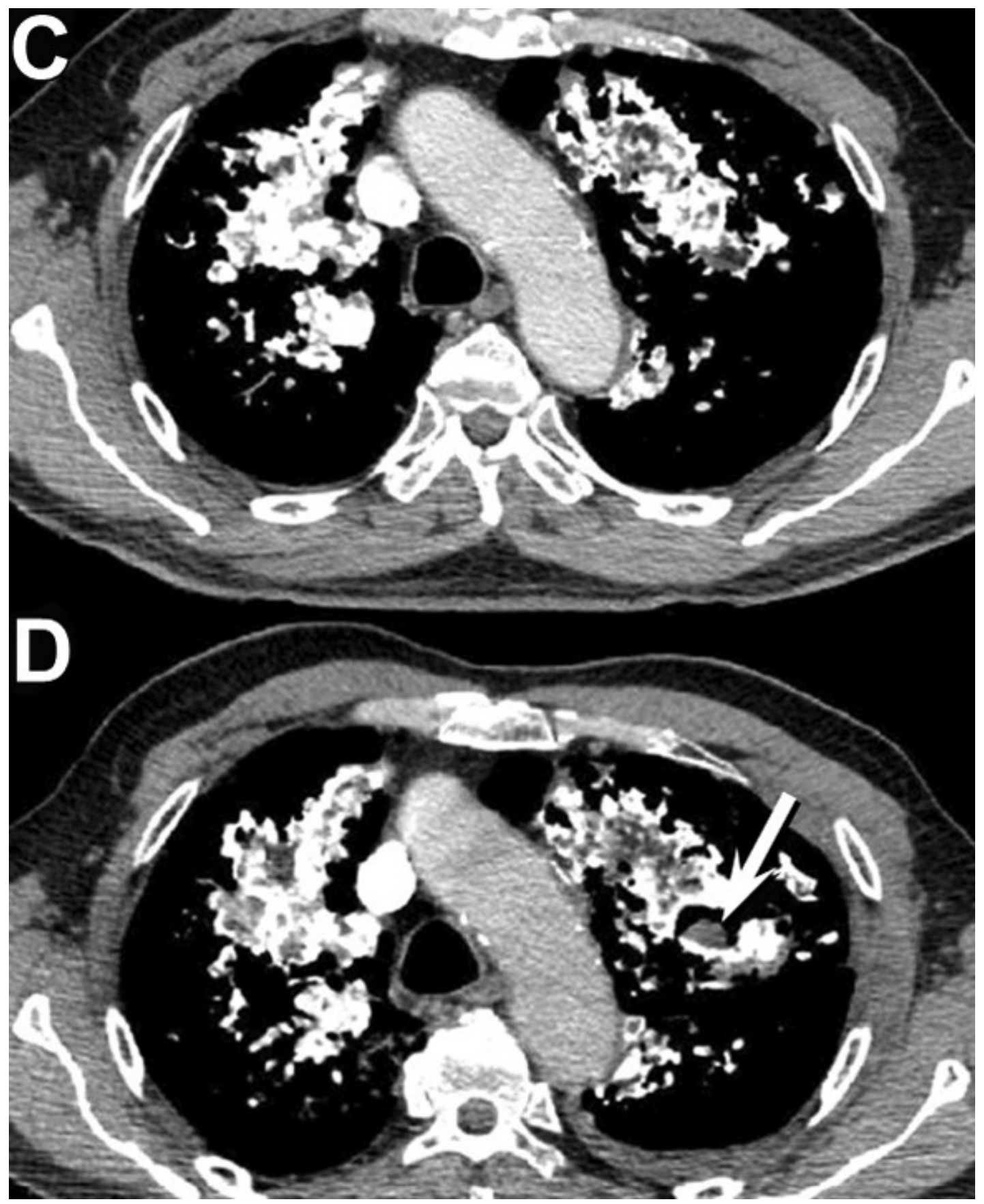

Figure $1 \mathrm{C}$ and D. Axial thoracic CT displayed in soft tissue windows shows extensive bilateral nodular hyperattenuating tissue consistent with alveolar septal / diffuse pulmonary parenchymal amyloidosis. A cystic lesion with internal, dependent soft tissue attenuation (arrow, D) is present, consistent with a hematoma.

This soft tissue-filled cavity was located at the same level as the rib fracture, surrounded by calcified tissue, and presumably reflected a pulmonary parenchymal hematoma resulting from traumatically induced laceration of the inelastic calcified lung tissue. 


\section{Discussion}

Pulmonary amyloidosis is a rare disease resulting from the extracellular deposition of insoluble fibrillar proteins aggregating in a $\beta$-pleated sheet configuration (1). Amyloidosis is classified according to the chemistry of the amyloid protein as AA secondary amyloidosis (SAA protein) -often related to chronic inflammatory diseaseAL amyloidosis (monoclonal immunoglobulin light chains of the lambda or kappa type)-secondary to B lymphoproliferative disorders-and hereditary or familial amyloidosis (transthyretin and gelsolin). Dialysis-associated amyloidosis $\left(\beta_{2}\right.$ microglobulinemia) and "senile" amyloidosis SAA (wild-type transthyretin) are also recognized. Pulmonary amyloidosis may occur in three forms: tracheobronchial, nodular parenchymal and alveolar septal / diffuse parenchymal patterns (2). The two first forms (which include primitive pulmonary amyloidosis) are often remain localized to the respiratory system, whereas the alveolar septal / diffuse parenchymal form of amyloidosis, whose prognosis is more severe, often presents in a systemically. Parenchymal amyloid nodules grow slowly and generally remain asymptomatic but patients may also present with dyspnea, cough, hemoptysis or recurrent pneumonia (3).

\section{References}

1. Chu H, Zhao L, Zhang Z, Gui T, Yi X, Sun X. Clinical characteristics of amyloidosis with isolated respiratory system involvement: A review of 13 cases. Ann Thorac Med. 2012 (4):243-9. [CrossRef] [Pubmed]

2. Gilmore JD, Hawkins PN. Amyloidosis and the respiratory tract. Thorax. 1999;54:444-51. [CrossRef] [PubMed]

3. Vieira IG, Marchiori E, Zanetti G, Cabral RF, Takayassu TC, Spilberg G, Batista RR. Pulmonary amyloidosis with calcified nodules and masses - a six-year computed tomography follow-up: a case report. Cases J. 2009;2:6540. [CrossRef] [PubMed] 